\title{
What a Difference a Decade Makes: Rethinking Teenage Pregnancy as a Problem
}

\author{
Lisa Arai \\ Faculty of Health and Social Care, The Open University \\ E-mail: I.arai@open.ac.uk
}

The Teenage Pregnancy Strategy (TPS) has been implemented in England since 1999 and has two aims: to halve under $18 \mathrm{~s}$ conceptions; and to reduce the risk of social exclusion among young mothers. The TPS portrays young motherhood as problematic, the cause of poor outcomes. Yet, the problematisation of teenage fertility has been contested, especially by qualitative researchers who have demonstrated that early motherhood can be experienced positively. This research is discussed here, as are findings from a smallscale study in three English locations, where teenage mothers reported good experiences of parenthood. The discrepancy between these accounts of motherhood and policy is considered.

\section{Introduction}

The resurgence of interest in early pregnancy and motherhood in recent years is largely attributable to the creation of the Teenage Pregnancy Unit (TPU) in 1999. The TPU was established to implement the Teenage Pregnancy Strategy (TPS), the goals of which are to halve conception rates among women in England aged under 18 and ensure that young mothers continue with education or employment after childbirth and do not become 'socially excluded' (SEU, 1999). The TPS was introduced in June 1999 when the UK government's seminal analysis of the 'problem' ('Teenage Pregnancy', SEU, 1999) was published. Initially, the TPS was to be implemented over a decade to the year 2010. Depending on geographic location, the TPS can run alongside other interventions aimed at boosting the life chances of children and young people living in deprived areas, such as Sure Start and Sure Start Plus. The focus of the latter, which came under the aegis of the TPS in 2005 (Wiggins et al., 2005), is on boosting teenage parents' educational and employment prospects.

In 1999, the TPS was considered a legitimate response to (perceived) ever-rising rates of teenage pregnancy and fertility. Yet there was actually a mismatch in timing between its introduction and the highest incidence of youthful childbearing. By the late-1990s in England and Wales, fertility rates for women under 20 were less than 30 births per 1,000 - a figure substantially below that of earlier decades (in 1970, this figure was around 50 per 1,000; Singh and Darroch, 2000). The conception rate for teenagers has fluctuated since the 1970s, but the overall trend is downward. Currently, less than one girl under 16 in every $100^{1}$ becomes pregnant in England and Wales (National Statistics, 2006). 
Many features of the TPS, especially those that promote greater educational and other opportunities for young mothers, have been welcomed by practitioners working with young people (Weyman, 2003). However, for the purposes of this paper, the introduction of the TPS is considered to have had a major negative consequence: the association of social exclusion with teenage fertility - a central plank of the TPS and one repeatedly drawn attention to within it - has reinforced the depiction of teenage pregnancy as a social and public health problem of some significance. It is argued here that, not only is this portrayal of early pregnancy not justified, but teenage motherhood can be experienced positively and bring benefits to young women and their families. An exploration of this is the focus of this paper.

\section{Teenage motherhood: a social and public health problem?}

Teenage motherhood is correlated with a variety of socio-economic, educational and health indicators of social exclusion. The major socio-economic and educational ones include low maternal educational attainment, relative deprivation, unemployment and residence in social housing (Berthoud et al., 2004; Hosie, 2007; Kiernan, 1997; Rosato,1999). The maternal health outcomes of teenage fertility include, for example, high rates of anaemia during pregnancy, postnatal depression and elevated rates of maternal mortality (Botting et al., 1998).

As other commentators have noted, correlation is not the same as causation, and it may not be maternal age per se that causes such poor outcomes (Duncan, 2007). Many of the health outcomes associated with fertility in the teenage years are attributable to factors such as poor nutrition, smoking in pregnancy and failure to utilise ante-natal care, for example, and not maternal age (except in the case of teenagers aged under 15) (Cunnington, 2001). There is now a growing body of work exploring the effects of early fertility (see Berthoud et al., 2004, for example), and there is no one, clear message that has emerged from it. Uncertainty about the consequences of teenage fertility is not sufficiently reflected in policy. Within the TPS, there is an acknowledgment that factors such as relative deprivation and poor access to services play a role in the creation of social exclusion, but there is still a strong tendency to see age itself as a significant, independent, explanatory factor (SEU, 1999).

Many analyses of statistical data have found negative outcomes for early motherhood, and it is these that are primarily used as 'evidence' to justify intervening to reduce early pregnancy (Graham and McDermott, 2006; Wilson and Huntington, 2006). As Wilson and Huntington suggest, the move towards evidence-based policy development has 'masked the ideological basis of much policy in this area' (p. 60). They advocate a re-examination of the discourses surrounding early motherhood and of the 'scientific' justifications for seeing teenage motherhood as a problem. Lawlor and Shaw (2002) make similar suggestions and ask that: 'Researchers and health practitioners should think more carefully about why something is labelled a public health problem' (p. 553).

\section{Young motherhood as a positive experience}

The recognition that teenage fertility does not always have calamitous consequences is the backbone of a body of work devoted to 'unpicking' the ideological basis of the 
TPS and similar interventions in the UK and elsewhere. This work has emerged largely over the decade since the introduction of the TPS, though there are some notable preTPS analyses questioning mainstream negative perceptions of youthful motherhood. In a British setting, Murcott (1980) wrote about the social construction of teenage pregnancy as a problem nearly 30 years ago. Other examples include Phoenix (1991) and Macintyre and Cunningham-Burley (1993) in the UK, and Geronimus (1997) and SmithBattle (2000, 2003) in the US.

Much of this work reports the findings of qualitative research, and it not only interrogates the assumption that early childbearing is problematic but goes further by suggesting that teenage motherhood can be experienced positively. A systematic review of the qualitative research on young motherhood in the UK (McDermott et al., 2004) questions contemporary approaches to teenage pregnancy, suggesting that young mothers take pride in being 'good' parents, and that teenage motherhood can be experienced positively even in the face of hardship and discrimination. These findings are similar to those of an earlier review by Clemmens (2003), where one of the main themes that emerged from analysis of 18 international studies was 'motherhood as positively transforming'.

Here, findings are presented from a larger research project ${ }^{2}$ which explored diverse aspects of young motherhood but was focused primarily on exploring peer and wider influences on behaviour and included analysis of cohort data alongside qualitative data. The experience of motherhood was not the primary focus of research, but one of the findings that emerged was that motherhood had benefits in ways that had not been anticipated before the study began. The aim here is to contribute to the relatively small body of qualitative research that challenges contemporary negative depictions of teenage fertility (especially as embodied in policy approaches like the TPS) by exploring young mothers' accounts of motherhood.

\section{Findings from a small-scale qualitative study in three English locations} Methods

Data were collected during face-to-face, semi-structured interviews with 15 women who gave birth before age 21. Young women were interviewed in Inner London, Northumberland and Greater Manchester. These are all areas characterised by relatively high teenage fertility rates, deprivation and poor employment prospects for young people. All the mothers came from working-class backgrounds. Most of the women were not in employment and received income support, though some worked part-time or were in temporary employment. One woman had entered higher education and the remainder (14) had either none, or the most basic (i.e. GCSEs), level of educational attainment. The average age at which women started childbearing was just over 17 years. Mothers were interviewed from a few weeks to approximately three years after they had first given birth, and were in their late teens or early 20s when interviewed.

The issues explored in the interviews were: women's family relationships, reactions to pregnancy, support offered to women and women's experience of being young mothers within the wider community. The interview data were transcribed and thematically analysed. This entailed reading and re-reading the transcripts to establish emerging themes (Aronson, 1994; Rice and Ezzy, 2000). In the larger study, which explored various 
aspects of the women's lives and drew heavily on ecological perspectives that positions individuals as being influenced by factors operating at different social levels (personal, family, neighbourhood, wider cultural influences etc.) (Bronfenbrenner, 1979), analysis of qualitative data generated a number diverse themes. For the purposes of this paper, the relevant data have been re-organised thematically into three areas. In the first domain, at the individual level where reproductive behaviour may be linked to personal histories in a salient and profound way, findings are organised under the heading 'response and resolution'. At the second stage, 'acceptance and support', there is a moving out from the individual to the wider family, and a focus on the relationship between the young mother and family members. In the third, 'defence and coping', young women describe relationships in the wider community and attempts to defend themselves against prejudice by outsiders by focusing on the positive aspects of young motherhood.

\section{Response and resolution}

Several young mothers reported experiencing early life adversity. For most, this was of the kind that affects many young people, such as bullying or parental separation, and most reported recovering from its effects reasonably well. Three women in the study reported experiencing (arguably) the most extreme form of childhood adversity: removal from their families and placement in the English 'care' system. For these women, and for those who had poor relationships with parents but remained in the family home, motherhood can be seen as a direct response to adversity. In Suzy's case, her father's physical abuse of her mother meant that her emotional needs were not met:

If your home base is not structured, there's no foundation there, wherever you go, you gonna feel unbalanced because you haven't got no balance from the home... At home...you want to feel secure and comfortable. But I never did feel that.

Suzy said that the news of her pregnancy at the age of 16 was a joyful event. She wanted to be loved:

I didn't know how to get it. The only way I would be able to receive it is through having [daughter]. I remember on the day that I found out that I was pregnant... I was shouting out ' I am having a baby!'... I was happy.

Suzy's sister also had a child in her adolescence. Suzy believed that she and her sister were both 'looking for love', and this explained their early transition to motherhood. For Chloe, who was the youngest mother and who reported a history of clinical depression, her relationship with her mother had always been difficult and she made an explicit link between this and her pregnancy: 'I think [the pregnancy happened], because me and me mum never really got on, and I wanted something that was mine, something for me.'

For all the young women, birth was a positively transforming event: one which brought families together and healed breaches. Motherhood brought about a 'resolution' of long-standing problems. Donna, for example, came from a fractured family unit. Her mother so disliked her ex-husband (Donna's father) that: 'She used to be sick if she saw him, she just couldn't stand it. That's how me mum were about me dad, when she seen 
him.' Yet the birth of her son led to a transformation in family dynamics. Donna's parents rallied round after she became pregnant: 'Me mum helps out a lot. Me mum got me all this furniture. Me mum and me dad together.' She says of her son that: 'When he were born. He brought us all together.' Motherhood helped Donna see how much she loved her mother:

I never knew how much I love me mum till I got pregnant. She gave me so much support. 'Cause every teenager hates their mum and dad, don't they?... I love her to bits now.

This was also true of Chloe, who had a strained relationship with her mother from her early teenage years: 'As soon as I had [son], everything changed, it's been brilliant...' Caroline also had a troubled family background. She did not have a good relationship with her stepfather, but the birth of her son was a catalyst for a change in family relationships:

With my stepfather, we never used to get along until I had [son] ... he doesn't treat us like a child anymore. Me and me mam we were never actually in the same room ... until I had [son], and we're like best friends now... She's realised that I'm old enough to have a child and I'm not a child myself anymore.

Despite these positive comments, the young women did not always initially react well to their pregnancies. Some women were fearful or uncertain when pregnancy was confirmed, and more than one briefly contemplated abortion:

We [boyfriend and respondent] didn't speak for two weeks after ... I wanted to be on my own and get my head round, and decide what I was going to do. Obviously the first thing that went through my head was abortion. I don't believe in them but I was only 15 and I had my whole life ahead of me, and it was going to stop us from doing this and that. (Caroline).

For Katie, the short duration of the relationship in which her son was conceived made her consider the use of abortion:

We [respondent and boyfriend] are against abortion. I thought he [boyfriend] was going to disappear as well, we don't have a strong relationship, and we've only been together a couple of months. And, that's when I started having doubts and then I thought 'I've got enough, I've got my mum ... I can't kill him, the baby', and so I went ahead with it.

Early motherhood was reported, then, to have had a positive impact on the respondents' lives and the lives of those around them, even when pregnancy was unplanned. For those young women who had previously had fraught relationships with parents, birth transformed family dynamics and healed breaches. For young women who had experienced the worst kinds of adversity, birth was described as a direct response to this. That teenage pregnancy can be a response to adversity is recognised within wider discourses on teenage pregnancy, and also within the TPS, but the 'resolution' angle is much less acknowledged. Instead, teenage motherhood is always depicted as having overwhelmingly negative consequences, and is usually portrayed as an event that tears families apart and hastens personal and social deterioration (SEU, 1999). 
The extensive support offered to young women by parents and other family members was tangible proof of acceptance of the young mother-to-be by her family. No woman reported being rejected by her family though, like the young mothers themselves, parents were not initially always happy about the pregnancy. Caroline said of her mother that: 'she was upset, but she wasn't really cross, she knew that I was having sex and that I was on the pill. It was my age really.' Hillary reported initially being shunned by her father though he later became a very loving grandfather. For Zaheda, her pregnancy came as a shock to her father: 'he [father] was so angry that I was pregnant. My dad couldn't believe it he kept saying 'Oh my God, she's a baby' and he was just completely mad at me.'

Charlie's disclosure of her pregnancy led to a 'telling off':

I got a little lecture off my dad when he found out... I think it helped the fact that I had been with [boyfriend] about three years. If I'd become pregnant after six months, I think my mum and dad would have gone ballistic.

Once parents had accepted their daughter's pregnancy, the support offered to the young women was considerable. Many of the women were able to work part-time (albeit in low-paid and temporary work), or attend classes because their parents offered help with babysitting. The kind of support offered to Caroline by her mother and father was extensive. In this case, Caroline's mother's own experience of being a young unmarried parent meant that she did not want her daughter to suffer as she had done:

Caroline (C): She didn't want me to go through what she'd had to. She was 19. That's why she's been here for us. My mam had nobody when she had me.

Int: Did she get kicked out when she got pregnant?

C: Yeah... I think that's why she's here, my mam never had a life when she had me. I go out on a Friday night. That's my night, and I go to school on a Thursday and I go to work on a Sunday, Monday, Tuesday, they're my nights. And, if I am really, really tired, me mam will take [son] out for an hour me so I can catch up on my sleep. She's really good like that. So is my dad.

Several other women also reported that their mothers had become pregnant in their teenage years, though often within a pre-marital courtship setting. Charlie's parents were engaged to be married when Charlie's mother became pregnant:

They got married at 18 . They had my sister at 18 , me at 19 and my brother at $20 \ldots$ they got married just in time!! She didn't lie to us. Mum told us that she got pregnant. They were getting married anyway.

The fact that a number of the respondents' mothers had started childbearing at a young age, parental acceptance of their daughter's pregnancy and the generous support offered to young mothers suggests that, in these families at least, early motherhood was not considered a terrible event. These observations contrast with the findings reported in the 1999 report on teenage pregnancy (SEU, 1999), where pregnant teenagers report hostile reaction to news of their pregnancy: 
I've just found out I'm pregnant. My mum gave me three days to decide on an abortion. When I told her I wanted to keep it, she threw me out. But I want to go back home. I miss her.

My dad threw my sister out when she got pregnant. He's hit her before. I'm so scared I think $I^{\prime} m$ going to run away.

I'm 15 tomorrow. I'm pregnant. The doctor told me I should have an abortion. My mum told me to get out and let social services put me in care. I just want to go home. (SEU 1999, 55)

There is no information in the report about how the data that led to the generation of these observations were collected or analysed, so no judgements about methodological robustness or representativeness can be made. The quotes in the report depict a picture of harsh parental rejection of the mother-to-be, and are curiously reminiscent of the treatment of pregnant young women in an earlier historical period. As already noted, these observations are at odds with the findings here, and also with those in the wider body of literature on teenage pregnancy which suggest that teenage mothers are often well-supported by their families (Allen and Bourke-Dowling, 1998; Macintyre and Cunningham-Burley, 1993).

\section{Defence and coping}

Young mothers' positive accounts of parenthood can be contrasted with their reports of hostility from others. Nearly all the women said that they had experienced antagonism towards them, though this usually took the form of isolated incidents and was not pervasive no women reported it affecting her daily movements, for example. The individuals responsible were usually older, unrelated people. It was not clear if hostility was related to perceptions of the mother's age or her marital status. Asked if they had encountered any hostility locally, Charlie and Yvonne mentioned older people giving them 'looks':

Not from my family and friends, people that care about me. But I did get the odd look on the street and off older people that are a bit more 'no sex before marriage'... .Yeah, I could see them looking at me and thinking 'She's a bit young' as I was pushing the pram. I could hear this man... [saying] ... 'You're too young to be a mother aren't you?' It was generally more men that said it, actually, than it was women.

Int: Do you think that people look down on you?

Yvonne: Some people do. The elder generation. They don't actually say anything, but it's the looks. They tend to give you looks... as if to say, you are too young to have that baby, sort of thing.

Even where they encountered hostility from other people, the young women were eager to point out that they benefited from becoming parents. The nature of these benefits varied. For Julie, having a daughter meant she was less lonely:

Julie (J): [A woman] who works in the High School... She was talking... [she said] 'I am old enough to be your mother', and I said 'I am a mother', and I said 'What are you shaking your head for?' She says 'You're pathetic. You've ruined your life.' And I said 'I'm quite happy. It has changed my life but it hasn't made it worse.'

Int: Has it made it better? 
J: Yeah. Because if [boyfriend] is working away, I've got someone there all the time to keep us company. I've got [daughter].

For Chloe, having a baby while young meant that you have your life (and your figure) when you are older:

Chloe (C) ... deep down I always wanted a baby, I wanted one young and there was no way I was getting rid of it

...

Int: Why?

C: So I can have me life... if I have me children first, when they're older, I'll still be young and I can do what I want ... people say 'Do you regret having him, you're so young now?' and I say, 'If could have had him younger, I would have done...'... Cause, at the end of the day, if they are looking down on me I just think... 'Well, when you are having your kids, my kids will be older and I'll have my body back and you'll be fat!'

Donna, like Chloe, thought it better to have children while young:

Lots of people have said to me that it's better to have your babies young and have your life after. Which I agree with now. I wouldn't tell someone to have a baby, no. It's not easy, no. But I have never found it hard like people say. They say 'Oh, it's awful.'

Macintyre and Cunningham-Burley (1993) maintain that many young mothers - who are often raised in larger families where they may have had responsibility for younger siblings - adjust well to motherhood. Caroline's experience of her time in hospital after the birth of her son confirmed this:

There was a woman there, she was 33 and I was helping her, you know, because I was 10 when me mam had [sister] so I knew everything...I was helping this woman who was 33, changing nappies!

Only two young mothers, Chloe and Suzy mentioned the disadvantages of young motherhood. In both these cases, these centred on not being able to go out with friends. None of the women said that they regretted having their children; all reported adjusting well to motherhood. Hillary said that, if she had her time again, she: '... wouldn't change anything. [It would be] exactly the same.'

Again, the accounts from the women in the study contrast with those made in the SEU report about young mothers' experiences of becoming a parent. One respondent quoted in Teenage Pregnancy says with evident sadness that:

Although I loved my son I cried for many years after he was born because I lost my independence and childhood, and I resented this. I lost many of my friends through no longer being able to socialise with them. I became very lonely and felt isolated. This life was not glamorous, instead it was lonely and for years I resented this because I wanted to go clubbing and wear nice clothes. (SEU, 1999: 62)

While there may be some similarities between aspects of this young mother's experience and findings here, this observation seems extremely pessimistic in comparison. 
The young woman acknowledges love for her son, but does not mention any benefits from becoming a mother; motherhood led, instead, to many years of tears. It is also worth noting that babies tend to restrict the movements of all mothers, regardless of age, and a common observation among new mothers is that they are confined to the home in a way they had not been previously (Choi et al., 2005).

\section{Discussion}

The TPS has been implemented in England for nearly a decade and, in that time, a body of research, often reporting findings of the analysis of qualitative data, has emerged that re-examines the portrayal of teenage pregnancy as a problem and is often critical of contemporary policy approaches to teenage pregnancy.

The findings here resonate with this work. Women reported motherhood as having benefits, primarily in that it healed family breaches and brought estranged family members together. This was especially the case where women had experienced early life adversity. Popular images of young mothers often depict them as unsupported and alone. Here, women were well-supported and their parenting status was accepted by their families (even though not all parents initially welcomed pregnancy). Many young women were able to work or study with the help of their families. Macintyre and Cunningham-Burley's (1993) observation that teenage mothers are often well-supported and that the loneliest and least well-supported mothers are middle class, married women geographically distant from their families was confirmed here. Against a national picture of low pay, family-unfriendly working practices and the difficulties and expense of securing suitable childcare, the women in the study were assisted in a way that would be unthinkable to many older women. This is not to imply that the young women did not struggle; there seemed little hope of decently paid and satisfying work in their areas, and women reported sporadic episodes of hostility from others in their neighbourhoods. However, supported by their parents, they coped well with the transition to parenthood and were keen to point out the benefits of early motherhood, especially to those strangers who judged them.

There are at least three possible limitations to the study. Because the findings reported here are secondary to a larger piece of research, one limitation is that there was little exploration of the negative aspects of motherhood. It is possible, of course, that young mothers (like older mothers), regard motherhood has having benefits and drawbacks. This is something to be explored elsewhere. In addition, the sample was relatively small, and women were recruited in three locations only, so no claim to representativeness can be made. Finally, in an Australian study of teenage mothers (Kirkman et al., 2001), the possibility is raised that the respondents are using a 'consoling plot' in their accounts. That is, the belief that young motherhood is beneficial facilitates:'an interpretation of the vicissitudes of life in a way that makes them bearable' (p. 287). It is stressed by the authors that a consoling plot does not mean that respondents are deluding themselves. Rather, by using such a device, the young mothers 'emphasise the positive' aspects of motherhood and acknowledge its drawbacks. These authors counter the suggestion that their respondents are deluding themselves (to the reader at least), but the possibility that individuals (especially those in apparently straitened circumstances) are capable of self-deceit is a reasonable enough one, and it is one that might be applicable here. Interestingly, the reasons cited for the benefits of early motherhood in the Australian study 
are similar to the ones reported here: that young mothers will be free in the future (when others are tied down), and that children bring families together.

\section{Implications for research and policy}

Before considering the implications of the findings, the point made earlier about the TPS being welcomed by practitioners needs to be reiterated. Funds have been allocated for supporting young women through the provision of childcare allowing mothers to return to education or retrain for the labour force (Kidger, 2004), for example. Support groups have been established for young mothers - a welcome development given evidence of their reluctance to access mainstream services (de Jonge, 2001). It is not the aim here to suggest that the TPS is not worthwhile, but to highlight the role that it plays in perpetuating a wholly negative view of early motherhood, one that is at odds with the present findings and much of the qualitative research.

Four implications for research and policy development are suggested. The first of these is a call for policymakers to recognise that teenage motherhood can be a positive, and even rational, event in some contexts. The TPS was created to reduce early pregnancy among 'at risk' populations, ostensibly for the benefit of young mothers and their babies. Yet, among such groups, early fertility might be normative and even desirable (Jewell et al., 2000). It might have positive, not easily discernable or measurable, outcomes. Seen this way, the exhortation to delay fertility comes from a position that is white and middle class, and one with a longer life trajectory that accommodates extended periods of educational attainment, career development and, ultimately, partnership and family formation - in that order (Geronimus, 1997). In families and social networks where early fertility is relatively common, young women are likely to be accepted and well supported and, in these cases, it is not appropriate or helpful to depict teenage fertility as a problem.

Second, these findings highlight how powerful qualitative research can be in describing the lives of young mothers in a meaningful way. Qualitative research can provide a counterbalance to prevailing negative views of young motherhood which rely on statistical evidence (Graham and McDermott, 2006). Given that motherhood appeared to have a positive effect on the lives of the women in the study, statistical research focusing only on the negative outcomes of teenage pregnancy may be failing to measure the true impact of early motherhood. Such research might be more empirically meaningful if women's accounts of the benefits (and the hazards) of early motherhood were incorporated into the analysis. This would not necessitate a denial of the negative consequences of early motherhood - where these can be established, and which are likely to be more relevant in the case of younger teenagers. Duncan (2007) has drawn attention to the importance of young mothers' accounts of parenthood, and the discrepancy between these and policy perceptions of teenage motherhood. Similarly, Macintyre and Cunningham-Burley (1993) observe that the literature on teenage pregnancy focuses excessively on the negative aspects of early motherhood and none of its joys.

Third, researchers are urged to exercise caution about accepting something as problematic just because it is described in a 'scientific' or 'evidence-based' way (Cherrington and Breheny, 2005). Rates of teenage pregnancy are not increasing and the evidence that early fertility has deleterious outcomes is not conclusive. We are reminded 
that: 'If a situation becomes defined as a social problem, it does not necessarily mean that objective conditions have worsened' (Hilgartner and Bosk, 1988: 53-4).

Last, policymakers (and researchers) need to be careful about the dangers of creating representations of teenage pregnancy which contribute (inadvertently or otherwise) to the pathologisation of young parenthood. Those keen to see a reduction in teenage pregnancy cannot be blamed for failing to provide evidence of how young motherhood can be lifeenhancing; it simply does not fit with the 'story' of teenage pregnancy (Arai, forthcoming, 2009). This is not a practice confined to policymakers. In Kidger's (2005) exploration of teenage mothers' involvement in peer education, the contradiction between the women's enjoyment at being mothers and the negative view of young motherhood they presented to students in the classroom was highlighted. Speaking of her feelings about the interviews with the young mothers, Kidger says that there is only one acceptable story to tell about teenage pregnancy in such settings:

it was clear during my interviews that these young women had experienced... pleasure and fulfilment through being a mother to their children. However [they had to] make sense of these personal stories in the public context of the sex education classroom, where there is only one morally approved story of teenage motherhood, and that is one of danger. (p. 492)

From a policy perspective, and in keeping with this 'one story only' stance, teenage pregnancy is depicted as a problematic, or even pathological, behaviour. To say that this is unfair on young mothers is an understatement, though, in some respects, unfairness is the least problem. Young mothers are aware that they are not regarded neutrally, or treated fairly, by those around them (one young mother spoke recently about being perceived as 'human detritus' by those around her; Lavender, 2007). And there is evidence that the stigma associated with young motherhood is so powerful that young people believe it can lead to a kind of 'social death' (Whitehead, 2001). In fact, so strong are the perceived links between teenage motherhood and social exclusion that young mothers have become a 'demographic residuum' (Arai, forthcoming, 2009), an 'extreme' population group, distinct from the larger population (Chandola et al., 2001), and who suffer from fertilityinduced social exclusion. Carabine (2007) sees a modernising agenda in New Labour's approach to teenage pregnancy. The young mother - welfare dependent, geographically immobile, poorly educated and with apparently limited vision - is the antithesis of this agenda. In modern, advanced, highly skilled and fast-changing industrial societies, the worst thing to be is a residuum of any kind. In this kind of economic setting, early parenthood is represented as an archaic and chronically self-limiting behaviour.

Now that the TPS has been running for almost a decade, it is time to applaud its successes and re-assess it aims. One of the aims of the TPS is to promote opportunities for, and offer general support to, young mothers, but this has always played 'second fiddle' to the first aim: a reduction in teenage conception rates. Future policy efforts should be focused primarily on promoting the well-being of young mothers (and fathers) and their children and less on the depiction of teenage pregnancy as a problem in need of intervention.

\section{Acknowledgements}

Queen Mary and the University of London Central Research Fund provided funding for the research on which this paper is based. Thanks to Dr Martin Robb (The Open University) 
for helpful comments on an earlier draft of this paper, and to the two reviewers for their comments.

\section{Notes}

1 The 2006 conception rate for girls aged under 16 in England and Wales is 7.8 per 1,000 (Table 4.2, ONS, 2008).

2 As part of a doctoral study on teenage pregnancy and fertility, see Arai (2004).

\section{References}

Allen, I. and Bourke-Dowling, S. (1998), Teenage Mothers: Decisions and Outcomes, London: Policy Studies Institute.

Arai, L. (2004), 'Teenage pregnancy and fertility in English communities: Neighbourhood, family and peer influences on behaviour', Ph.D. thesis, Queen Mary (University of London), London.

Arai, L. (forthcoming, 2009), Teenage Pregnancy: The Making and Unmaking of a Problem, Bristol: Policy Press.

Aronson, J. (1994), 'A pragmatic view of thematic analysis', The Qualitative Report, 2, 1. Accessed online at: http://www.nova.edu/ssss/QR/Backlssues/QR2-1/aronson.html (checked 22/04/08).

Berthoud, R., Ermisch, J., Francesconi, M., Liao, T., Pevalin, D. and Robson, R. (2004), 'Long term consequences of teenage births for parents and their children', Report to the Department of Health, Institute for Social and Economic Research, University of Essex.

Botting, B., Rosato, M. and Wood, R. (1998), 'Teenage mothers and the health of their children', Population Trends, 93, 19-29.

Bronfenbrenner, U. (1979), The Ecology of Human Development: Experiments by Nature and Design, Cambridge, MA: Harvard University Press.

Carabine, J. (2007), 'New Labour's Teenage Pregnancy Strategy', Cultural Studies, 21, 6, 952-73.

Chandola, T., Coleman, D. A. and Hiorns, R. W. (2001), 'Heterogeneous fertility patterns in the Englishspeaking world: results from Australia, Canada, New Zealand and the United States', paper presented at the EAPS Population Conference, Helsinki, 7-9 June.

Cherrington, J. and Breheny, M. (2005), 'Politicizing dominant discursive constructions about teenage pregnancy: re-locating the subject as social', Health, 9, 1, 89-111.

Choi, P., Henshaw, C., Baker, S. and Tree, J. (2005), 'Supermum, superwife, supereverything: performing femininity in the transition to motherhood', Journal of Reproductive and Infant Psychology, 23, 2, $167-80$.

Clemmens, D. (2003), 'Adolescent motherhood: a metasynthesis of qualitative studies', The American Journal of Maternal and Child Nursing, 28, 2, 93-9.

Cunnington, A. (2001), 'What's so bad about teenage pregnancy?', Journal of Family Planning and Reproductive Health Care, 27, 1, 36-41.

de Jonge, A. (2001), 'Support for teenage mothers: a qualitative study into the views of women about the support they received as teenage mothers', Journal of Advanced Nursing, 36, 1, 49-57.

Duncan, S. (2007), 'What's the problem with teenage parents? And what's the problem with policy', Critical Social Policy, 27, 307-34.

Graham, H. and McDermott, E. (2006), 'Qualitative research and the evidence - base of policy: Insights from studies of teenage mothers in the UK', Journal of Social Policy, 35, 1, 21-37.

Geronimus, A. T. (1997), 'Teenage childbearing and personal responsibility: an alternative view', Political Science Quarterly, 112, 3. Accessed online at: http://www.psqonline.org/cgi-bin/99_article.cgi?byear $=1997 \&$ bmonth $=$ fall \&a $=03$ free\&format $=$ view (checked 22/04/08).

Hilgartner, S. and Bosk, C. L. (1988), 'The rise and fall of social problems: a public arenas model', American Journal of Sociology, 94, 1, 53-78. 
Hosie, A. C. S. (2007), "I hated everything about school": an examination of the relationship between dislike of school, teenage pregnancy and educational disengagement', Social Policy and Society, 6, 3, 333-47.

Jewell, D., Tacchi, J. and Donovan, J. (2000), 'Teenage pregnancy: whose problem is it?', Family Practice, $17,6,522-8$.

Kidger, J. (2004), 'Including young mothers: limitations to New Labour's strategy for supporting teenage parents', Critical Social Policy, 24, 3, 291-311.

Kidger, J. (2005), 'Stories of redemption? Teenage mothers as the new sex educators', Sexualities, 8, 4, 481-96.

Kiernan, K. E. (1997), 'Becoming a young parent: a longitudinal study of associated factors', British Journal of Sociology, 48, 3, 406-28.

Kirkman, M., Harrison, L., Hillier, L. and Pyett, P. (2001), 'I know I'm doing a good job': canonical and autobiographical narratives of teenage mothers', Culture, Health and Sexuality, 3, 3, 279-94.

Lavender, B. (2007), 'Young, gifted and pregnant', The Guardian, 31 March. Accessed online at: http://lifeandhealth.guardian.co.uk/family/story/0,,2046551,00.html (checked 22/04/08).

Lawlor, D. A. and Shaw, M. (2002), 'Too much too young? Teenage pregnancy is not a public health problem', International Journal of Epidemiology, 31, 3, 552-3.

Macintyre, S. and Cunningham-Burley, S. (1993), 'Teenage pregnancy as a social problem: A perspective from the United Kingdom', in A. Lawson and D.L. Rhode (eds.), The Politics of Pregnancy: Adolescent Sexuality and Public Policy, New Haven and London: Yale University Press.

McDermott, E., Graham, H. and Hamilton, V. (2004), 'Experiences of being a teenage mother in the UK: a report of a systematic review of qualitative studies', ESRC Centre for Evidence-Based Public Policy, Lancaster University.

Murcott, A. (1980), 'The social construction of teenage pregnancy: a problem in the ideologies of childhood and reproduction', Sociology of Health and Illness, 2, 1, 1-23.

National Statistics (2006), Conception Statistics in England and Wales, 2006 (Provisional), London: National Statistics.

ONS (2008), 'Conceptions for women resident in England and Wales, 2006', http://www.statistics.gov.uk/ downloads/theme_health/conceptions2006/conception_statistics_06_web.pdf.

Phoenix, A. (1991), Young Mothers? Cambridge: Polity Press.

Rice, P. L. and Ezzy, D. (2000), Qualitative Research Methods, Victoria, Australia: Oxford University Press.

Rosato, M. (1999), 'Teenage fertility in England and Wales: trends in socioeconomic circumstances between the 1971 and the 1981 censuses', Longitudinal Study (LS) Working Paper 78, Centre for Longitudinal Studies, Institute of Education, University of London, London.

SEU (Social Exclusion Unit) (1999), Teenage Pregnancy, London: HMSO.

Singh, S. and Darroch, J. E. (2000), 'Adolescent pregnancy and childbearing: levels and trends in developed countries', Family Planning Perspectives, 32, 1, 14-23.

SmithBattle, L. (2003), 'Displacing the rule book in caring for teen mothers', Public Health Nursing, 20, 5, 369-376.

SmithBattle, L. (2000), 'Developing a caregiving tradition in opposition to one's past: lessons from a longitudinal study of teenage mothers', Public Health Nursing, 17, 2, 85-93.

Weyman, A. (2003), 'Promoting sexual health to young people: preventing teenage pregnancy and sexually transmitted infections', The Journal of the Royal Society for the Promotion of Health, 123, 6-7.

Whitehead, E. (2001), 'Teenage pregnancy: on the road to social death', International Journal of Nursing Studies, 38, 437-46.

Wiggins, M., Rosato, M., Austerberry, H., Sawtell, M. and Oliver, S. (2005), Sure Start Plus National Evaluation: Final Report, Social Science Research Unit Report, London: Institute of Education.

Wilson, H. and Huntington, A. (2006), 'Deviant (m)others: the construction of teenage motherhood in contemporary discourse', Journal of Social Policy, 35, 59-76. 